\title{
Should We Teach Entrepreneurship In An Engineering School? Reflections and Recommendations
}

\author{
Nada Rih ${ }^{1}$, Professor Mohammed Guedira ${ }^{2}$ \\ 1,2 (Department of Education sciences, Mohammed V Souissi University, Morocco)
}

\begin{abstract}
The question of integrating entrepreneurship programs in higher education has largely been debated during the latest years. The benefits of this education are today well recognized by schools, universities and politics as well.

The personal acquisitions related to entrepreneurship education are considered as significant mainly to differentiate the students and allow them to develop new abilities that were not considered by traditional education.

Following a study of two years in a Moroccan engineering school, this article offers a general view of the results of a pilot experience of an entrepreneurship program as well as a digest of the conclusions related to the advantages, difficulties and recommendations for entrepreneurship education within this environment.

This paper has two objectives: from one hand is to give a general overview of the conducted study's concluding remarks; and from another hand, to share our reflection about the subject of introducing an EEP (Entrepreneurship Education Program) in an engineering school in Morocco.
\end{abstract}

Key words: Entrepreneurship education - engineering school - assessment - Entrepreneurial intention resistance.

\section{Introduction}

The integration of entrepreneurship education programs in higher education is nowadays a hot topic in many countries around the world.

The teaching of entrepreneurship has since the late 80s gained legitimacy in developed countries, in particular in the United States before joining the European schools and universities.

Indeed, there are several dimensions and social interests, including the political and the economic, that support the integration of entrepreneurship education into the curricula of conventional teachings. In fact, it meets the objectives of a country's success in economic, political, social and technological levels. It encourages people to conscious risk taking through the development of new businesses and new values.

From a political point of view, entrepreneurship education is generally associated with the economic development through a tangible added value and employment opportunities.

For universities and schools, the courses linked to entrepreneurship give their students the opportunity to develop transverse skills. This can constitute for them a differentiation strategy over competing institutions.

Finally, students perceive entrepreneurship education as an added value to their education and professional career (Verzat and Surlemont, 201) [1].

Entrepreneurship education is now a well recognized field within entrepreneurship research. From this particular field, we can define various research subjects such as the entrepreneur's profile evolution; the project's feasibility...

In addition, the role of the educational system has become of great importance in the development of the entrepreneurial spirit. It can provide young people with a taste of entrepreneurship. Even if these young people do not engage in an entrepreneurial career, they will have acquired the necessary behavior to act in an entrepreneurial manner that will allow them to adapt to change, to act independently and to develop their abilities to make initiatives within an organization.

Drucker (1985) [2] says that entrepreneurship is a discipline that can be taught like any other discipline.

Furthermore, other authors point out that we are not born entrepreneurs. Entrepreneurship is viewed more as a behavior, an attitude, which can be encouraged and developed.

Through a research of three years in an engineering school in Morocco, we studied the results of a pilot experience of an entrepreneurship program. We also completed this research by analyzing the main points around the introduction of this education, such as the objectives, the educators profile, the resistance, etc....

This paper aims to highlight the main issues related to entrepreneurship education in general and in a Moroccan engineering school in particular. It will also present some important results of the study conducted with the aim of testing the impact of an EEP in a Moroccan engineering school. 


\section{Entrepreneurship Education}

The definition of entrepreneurship education, in itself, has raised many questions and discussions, with some differences of opinions, among researchers that led to a lack of a common definition.

A discussion was held about the use of "Entrepreneurship Education" or "Business Education". The term entrepreneurship education has even been sometimes replaced by "the entrepreneurial education". There has often been a sort of confusion as to the area covered by entrepreneurship education.

Fayolle et al. (2006) [4] define EEP (Entrepreneurship Education Program) as an educational process that allow the acquisition of entrepreneurial attitudes and skills, including the development of some personal behaviors. It is however not focused on the immediate creation of a new business.

Some authors argue that there is a conceptual difference between entrepreneurship education, which focuses on creating an independent attitude and business education that seeks to create individuals looking for opportunities. Other authors such as Gibbs (1993) [6], believe that these two terms are similar from a conceptual point of view but differ contextually since entrepreneurship education is mainly used in the USA and Canada and business education is rather used in England and Ireland.

However, even if these terms are used interchangeably in the literature, "entrepreneurship education" still remains the most commonly used and serves as a generic nomenclature for these educational processes.

Entrepreneurship education is nowadays gaining the support of many proponents in the society. On one hand, politicians who believe increasingly that this is an area that deserves the effort and the money invested. And on the other hand, recruiters, who are beginning to recognize that the profiles trained for entrepreneurship, can bring a degree of innovation to their business.

Moreover, these programs can bring an early awareness of the labor market as it provides the practical skills needed by entrepreneurs when they are ready to start their business.

The UNESCO (1998) also argued that the development of entrepreneurial skills should be a major concern in higher education. It would be an opportunity to help students, which will become job seekers, improve their employability.

While traditional approaches to education are recognized by their effectiveness in relation to the acquisition of knowledge, they have nevertheless shown their limits as to skills acquisition.

Today, new methods have been introduced to highlight the concept of skills and are identified by different names such as: skills approaches, behavioral skills, soft skills, etc..

After their appearance in the U.S. in the 80s, these methods, qualified as a "rupture" with the past pedagogies, are increasingly introduced in the educational systems of many developed and developing countries (Aouni, 2011) [8].

The entrepreneurship education is very different from other areas of education. It requires the development of skills beyond traditionally acquired "knowledge" and "know-how". It rather requires the development of skills qualified as the "ability to act" facing complex situations within an uncertain and unpredictable environment.

To this end, entrepreneurship education must adopt an approach that promotes the development of skills, abilities and expertise to start a business.

The ability of the learner to engage in entrepreneurial situations depends highly on the integration of transversal skills, knowledge and motivation.

In fact, in order to allow them to acquire the "know how to act" skills, we have to think about entrepreneurial situations facing new entrepreneurs and identify the resources that would allow them to cope with these situations.

A "philosophy" said constructivist has recently emerged to define a new method of learning in entrepreneurship education. This method recommends that the learner should be directed to knowledge acquisition through active participation. This will allow him to develop cognitive and metacognitive strategies to manage knowledge and develop understanding (Aaouni, 2011) [9].

Moreover, learning through direct experience rather than through abstract concepts allows the learner to perceive the usefulness of what he learns, making the process more motivating and developing the ability to mobilize his resources. The responsibility of the learner and thus also engaged in the learning process (Verzat, 2011) [10].

Other authors such as Bureau and Fendt (2011) [11] have even suggested that we should use new addons to the methods used in the field of entrepreneurship education such as "situational drift." These methods, originated by a revolutionary art movement of the $50 \mathrm{~s}$, immerse students in an unexpected experience that would overstep their usual comfort zones. The objective is that the realization of a drift can create a situation that would foster creativity, imagination and would give a different view of reality and opportunities.

This is demonstrated by the following principles:

- Work without a clear objective and developing opportunities progressively;

- Generate resources; 
- Develop creativity;

- Adopt a critical posture;

- Manage group dynamics during a crisis;

- Learn from failures.

These researchers argue that the drift can reveal "in vivo" participant's entrepreneurial skills and would highlight important inputs that were not expected.

\section{Objectives Of Entrepreneurship Education}

The purpose of entrepreneurship education has been widely discussed by the research community in the field.

In recent years, entrepreneurship and entrepreneurship education were considered as a solution to the decline or stagnancy of economies in both developed and developing countries.

For economies in transition, entrepreneurship education has become an integral part in the new curriculum of higher education. It is also considered as an effective way to facilitate the transition between education and the professional career.

Entrepreneurship education was then pushed to the top of the political agenda and has become a priority for developed and developing countries policy makers.

Since the first course given at Harvard Business School, many researchers were interested in the phenomenal development of entrepreneurship education. Several studies have traced this development and the state of entrepreneurship training (Pittway and Cope, 2007; Kuratko, 2005, Solomon et al, 2002. Vesper and Gartner, 1997; Garavan and O'Cinneide 1994a, b; Hills, 1988) and all have identified a remarkable progress in the field (Mwasalwiba, 2010) [12].

The development of educational programs in entrepreneurship worldwide, however, demonstrates the importance of this situation. Some researchers noted the early development in the U.S. from one institution that offered entrepreneurship courses in 1945 to 16 business schools with specific programs in 1970. In 1995, there were more than 400 universities that offered entrepreneurship education programs to their students (Matlay, 2006) [13].

Research studies in the field showed that most entrepreneurship programs in universities have the following objectives:

- Identify and foster entrepreneurial spirit, skills and talents;

- Develop autonomous behavior; and

- Acquire a general understanding of business start-ups and management skills.

In fact, for students, the objectives of entrepreneurship education can range from awareness, learning, capacity building, knowledge and skills acquisition, and we even talk recently about the "acting knowledge".

Fayolle (2011) [14] summarized the learning types related to the entrepreneurial act as follows:

- The "know why" (attitudes, values, motivations ...);

- The "know what" (what to do to start a business);

- Know-how (how to go about starting a business);

- The know who (people and useful networks);

- Know when (what is the right time to start).

These learning types seem of great importance for the development of an entrepreneurial profile. However, adding a component related to the development of behavioral skills seems very important to us.

Furthermore, nowadays students are not often faced with situations that encourage the development of entrepreneurial skills such as negotiation, taking initiatives, recognizing opportunities, perseverance or management failure.

However, some skills such as motivation and self-confidence were recognized for their power to fight against school failure, to promote youth development and help build autonomous and responsible individuals (Verzat, 2011) [15].

Today, behavioral skills are recognized as important as disciplinary skills within this type of education programs whether it is for future entrepreneurs or not.

It is, in our point of view, very important to develop these skills among engineering students often much more oriented toward scientific disciplines. Even if these skills are not necessarily used in an objective of business creation.

Although it is commonly accepted that it is difficult to assess these skills, it was nevertheless recognized that entrepreneurship education would enable the acquisition of capacities associated to a "know how to act" which would help managing complex situations.

To this end, the real purpose of this kind of training is to develop the ability to identify entrepreneurial situations and to combine and implement the necessary resources for an effective usage. 
The learners should be able to combine their knowledge, skills and attitudes to be able to act effectively in complex situations.

\section{Assessing The Impact Of A Pilot Eep On Entrepreneurial Intention The Case of an Engineering School In Morocco}

INPT (Institut National des Postes et Télécommunications) is one of the leading engineering schools in Morocco. It trains more than 200 engineers per year for the Telecommunication and Information Technology sector.

The study concerned a group of 20 INPT students, mostly in the second year of their engineering curriculum that were selected to follow the EEP. These students have presented an idea of business creation and applied to follow the PEE. They were selected by a jury from a large number of students.

The study was conducted over a period of two years. We participated in the establishment of the EEP at INPT: from the project selection, courses lay out, monitoring and training. We also worked closely with students on their projects.

The training took place over a period of 05 months with, on average, one session per week (outside holiday periods or examinations).

Research data were collected through three stages:

- First, a questionnaire was administered before the training to all participants in order to measure the variables at T0. A plenary session was held with all participants and we explained the purpose of this study before collecting the data.

- The second questionnaire was administered after the training period in order to check out the evolution of the variables with the training. The questionnaire was administered individually to initiate discussion with the participants and identify the positive and negative aspects of this experience. The objective was to generate a reflection for establishing such a program within the school.

- The third step was to get back to the students after graduation and determine the stability of the collected results as well as exploring the evolution of the studied variables.

In addition, throughout the process, we observed the students evolution, interests and reactions in order to develop a comprehensive picture of this experience.

\section{Research Model:}

Our research model is based on a combination of three well renowned models in the field of entrepreneurship with the objective of assessing the impact of EEP on the entrepreneurial intention. These models can briefly be presented as follow:

\subsection{The Theory of Planned Behavior Ajzen (1991) [17] (TPB):}

This theory has received considerable empirical attention in the field of entrepreneurship. In this theoretical framework, the development of entrepreneurial intention depends on: the attitudes with regard to the perceived behavior, the subjective norms and the perceived behavioral control, which gives a good predictor of behavior.

We recall that the central point of the TPB is the intention of the individual to have a given behavior. The main assumption is that the intention is the result of three conceptual determinants:

- The attitude toward the behavior: the degree to which a person has a favorable or unfavorable evaluation of the behavior in question;

- Subjective norms: perceived social pressures to perform or not the behavior. This means the subject's perception of people's view of the proposed behavior;

- Perceived behavioral control: The difficulty or ease perceived to perform this behavior. This concept is similar to the concept of perceived self-efficacy (Bandura, 1982) [18].

For the TPB, these three factors are the antecedents of intention and they can influence future behavior.

\subsection{Shapero and Sokol Model (1982) [19]:}

This model aimed to support the construction of the entrepreneurial event. The authors raise the paradigm of the entrepreneurial event's construction. First, there is a "displacement" as the beginning of the entrepreneurial process and then the perception of desirability and feasibility leads to the formation of the entrepreneurial event. Even if the authors do not explicitly use the concept of intent, however it appears that there is a strong link between intention, desirability and feasibility (Fayolle et al., 2006) [20]. Yet, even though this model is validated and compared with the theory of planned behavior model, it focuses only on business creation, not evolution towards the adoption of entrepreneurial behavior. 


\subsection{Krueger and Brazeal model (1994) [21]:}

This model is very much inspired by the Shapero's model of entrepreneurial event (1982) and Ajzen's theory of planned behavior (1991). It highlights the importance of perceived feasibility (personal efficiency) and perceived desirability (attitudes, social norms).

This study is mainly based on the theory of planned behavior since this theory has been applied in several studies and has been tested empirically, providing validated research material (Fayolle et al. 2006) [22]. However, we thought that it would be interesting to include some givens from other models to provide a general picture of the evolution of the studied subject's behavior.

Figure 1: Research Model

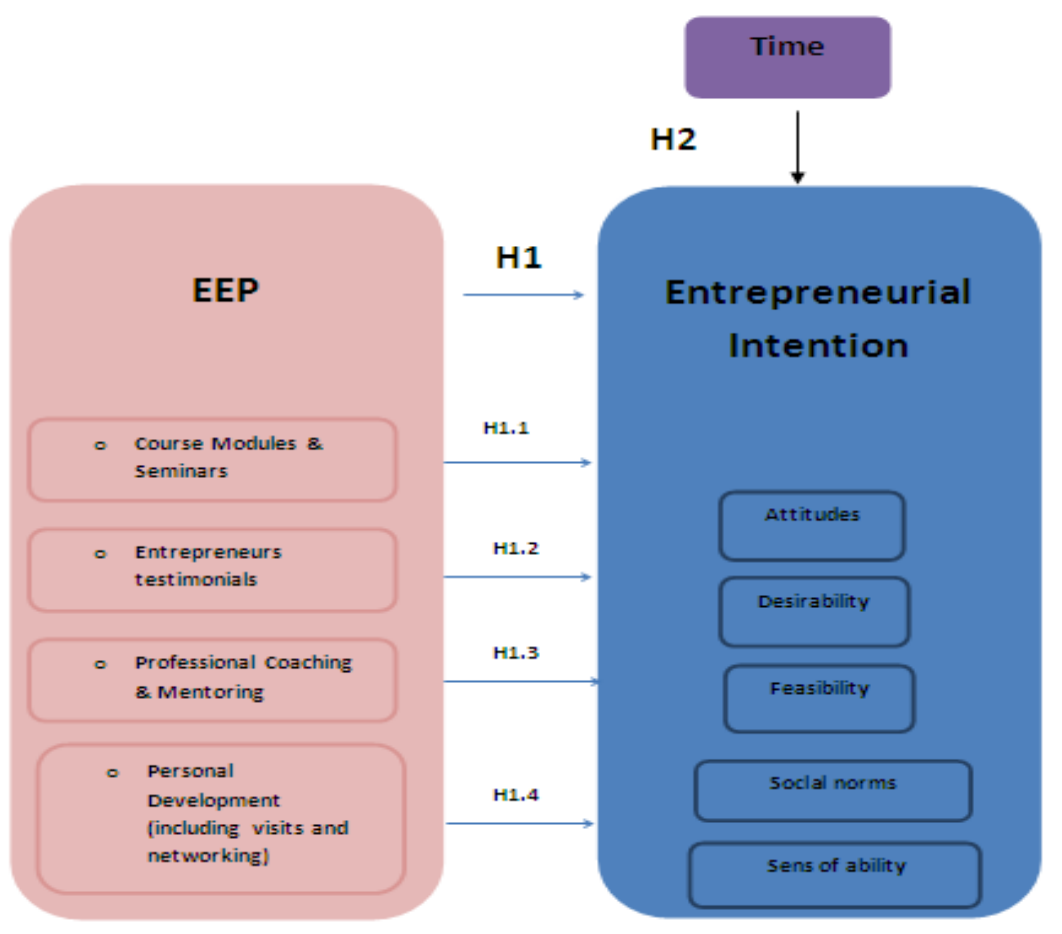

VI. Research hypothesis:

Hypothesis 1: An Entrepreneurship Education Program (EEP) positively impacts the entrepreneurial intention.

- Hypothesis 1.1: The courses and seminars modules act positively on entrepreneurial intention.

- Hypothesis 1.2: Entrepreneurs testimonials affect positively the entrepreneurial intention.

- Hypothesis 1.3: The coaching / mentoring affect positively the entrepreneurial intention.

- Hypothesis 1.4: The personal development affects positively the entrepreneurial intention.

- Hypothesis 1.5: The practical workshops act positively on entrepreneurial intention.

Hypothesis 2: After the end of the EEP, the time impacts negatively the entrepreneurial intention.

In the present paper, we will present only some concluding results of the overall collected data. Subsequently, we will not go into the details of the program components.

\section{Methodology:}

The study has been conducted through tree major steps:

- The first step before the EEP;

- $\quad$ The second after the EEP;

- $\quad$ And the third, one year following the EEP.

The data collection was conducted through questionnaires and was completed with the observation of the individual and group evolution through the overall period.

As content analysis is one of the most used techniques in the field of humanities, this method was used to conduct the analysis of the interviews results for this study. It allowed us to achieve an objective and systematic description of the transcribed script contents, and a faithful interpretation of the answers. Categorization of the results permitted a combination of all speech elements with the same nature.

The content analysis was conducted through 4 main steps: pre-analysis, categorization, coding and counting, and results interpretation. 
Following, a speech analysis was conducted through the method of the propositional discourse analysis with the software Tropes.

Even if the size of the collected data was not very large, we decided to use a software in order to highlight the core corpus. This allows a clear presentation that highlights "the universe of reference" of the studied variables. In addition, the use of a software allows more subjectivity in the research.

From another hand, as mentioned previously, the observation of the group and individual evolution helped develop an overview of the observed group and the different variables of the situation. The observation results were not presented separately, but incorporated directly into the analysis framework to support its results. All these different methods allowed us to conduct a triangulation of methods to ensure complementarities and a global presentation of the results.

\section{Some primary results:}

The results presented in this paper will cover only the general impact of the PEE on the intention. The study however took into consideration, the impact of each component of the program on the studied variables that will be presented in a future article.

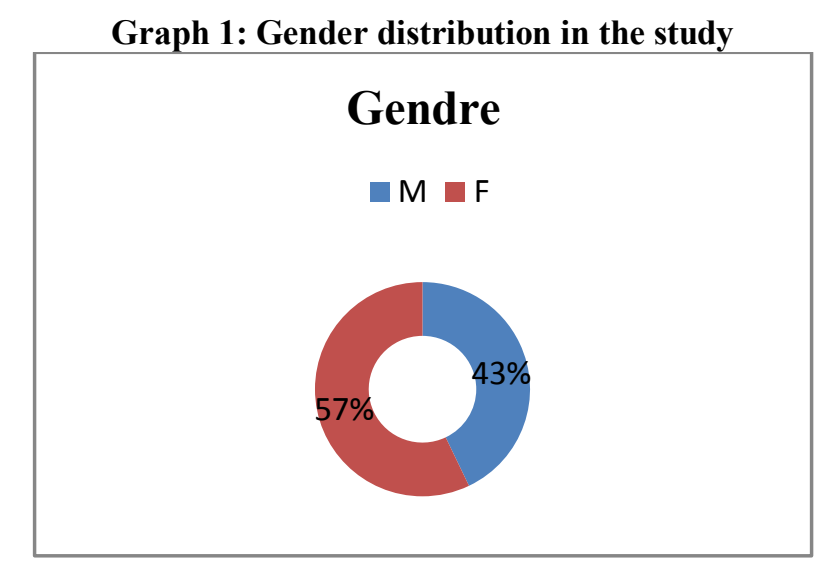

We can notice from this graph that there are more female students then male. This testifies that even if there is a cultural context that is generally unfavorable for women in entrepreneurship, these are more and more interested by the entrepreneurial career.

Graph 2: The emergence of entrepreneurial intention

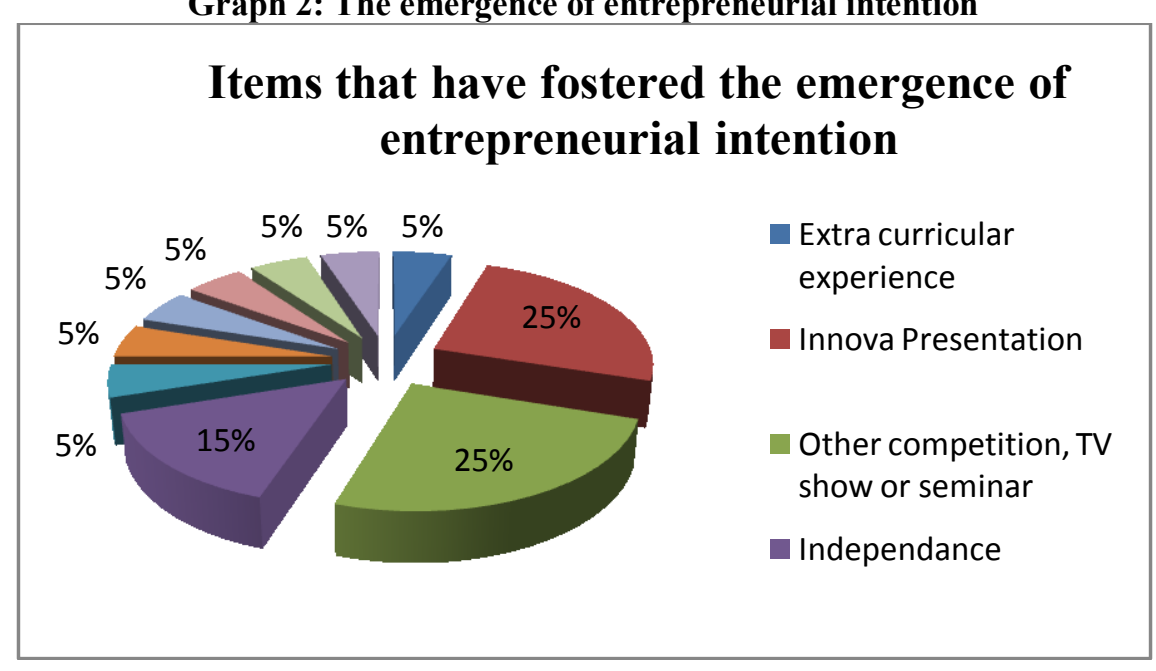

We can point out from this graph that there are some experiences that can foster the emergence of entrepreneurial intention. For our group, the presentation of the EEP (Innova project) and entrepreneurship competitions, seminars and TV shows seem to be the most important for developing entrepreneurial intention. These are followed by the need of independence generally linked to the entrepreneurial career. 


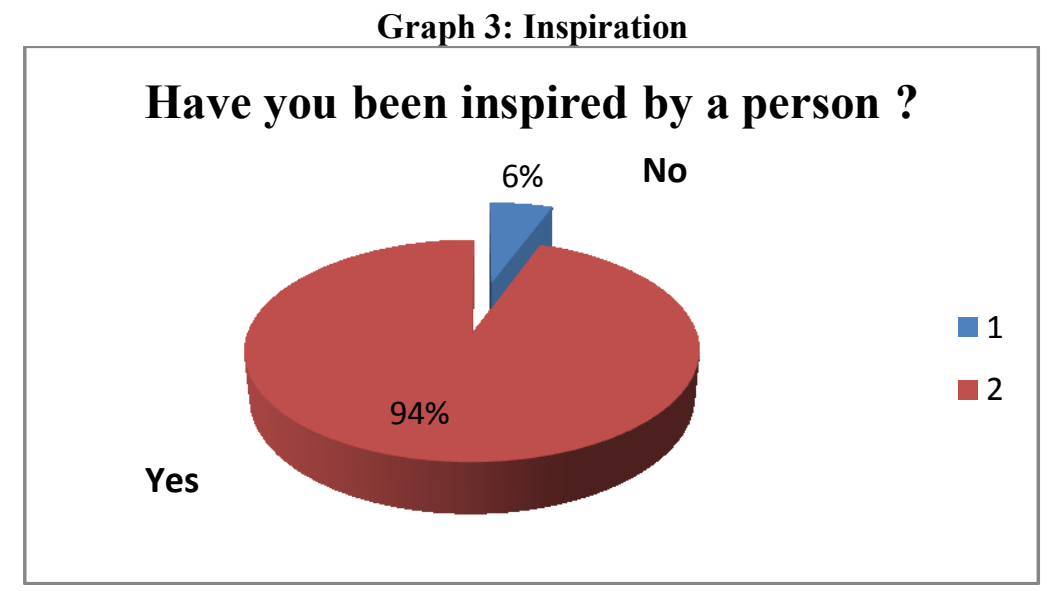

More than $90 \%$ of the participants to the EEP say that they have been inspired for considering an entrepreneurial career. Role models seem to us a very important component of entrepreneurship education.

Graph 4: The entrepreneurial intention evolution through the 3 steps

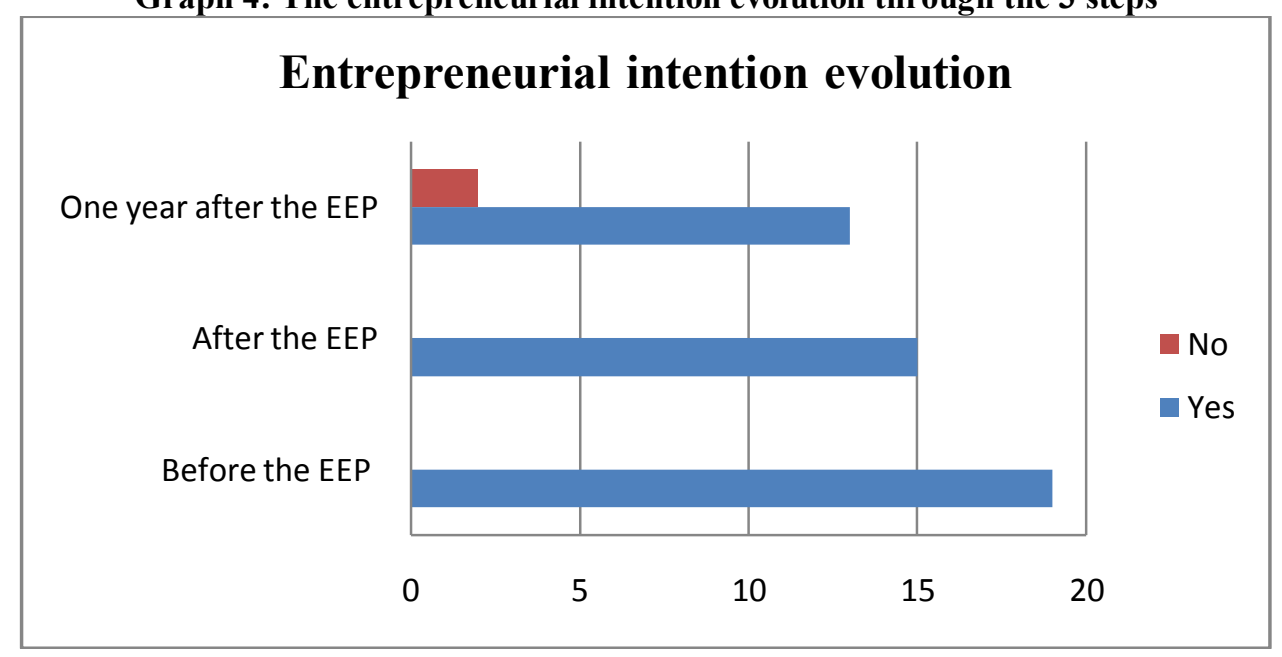

From this graph, we can see that entrepreneurial intention is stable before and after the EEP but it starts to decrease one year after the EEP. An individual analysis of the profiles who gave up the idea of business creation raised the following conclusions:

- Both profiles are girls: this gives us an indication about the fact that the local culture does not generally encourage entrepreneurial career for women.

- $\quad$ Both subjects have a positive desirability. They also have a clear perception of their attitude.

- Paradoxically, both subjects participated in extracurricular activities during their years of study at the engineering school.

- Both subjects were affected by at least one person. However, for one of them, the effect of the EEP was mitigated with a particular awareness of the difficulties. This can be justified with the fact that a year after the EEP, the first person prefers a less stressful career (in fact in research) despite the attractiveness of the field of entrepreneurship. Regarding the second person, the effect of PEE was positive, however she does not want to take such a responsibility and would like to experience first the professional world. 


\section{Graph 5: Perception of feasibility}

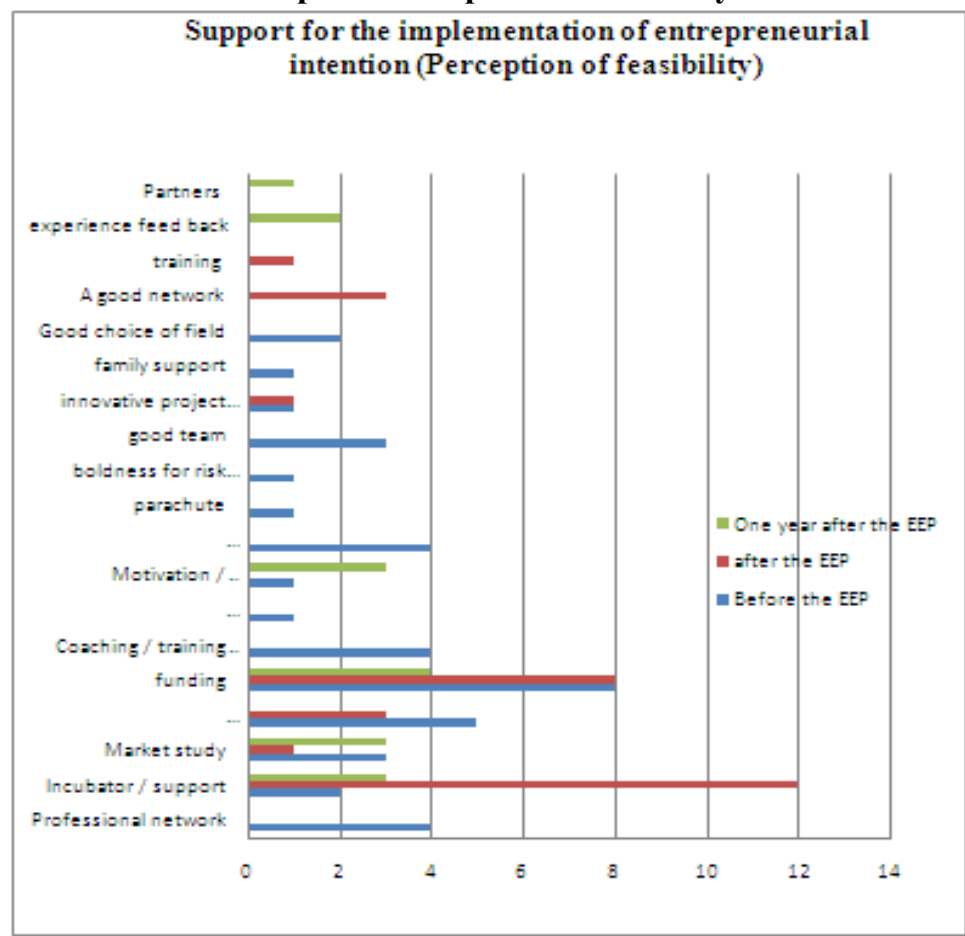

This graph shows the evolution of the feasibility perception through the three stages. The elements that are recurrent on the three stages are:

- The Funding: which is an important factor raised in the three steps even if there is a decrease in the third stage;

- The Support and Incubation: these points peaked in the period after the EEP. This can be explained by an awareness of the participants through the EEP and then to a lower extent through the market study.

- $\quad$ Some other elements such us Training and network are also raised after the EEP and others one year after the EEP such as training and entrepreneur's feedback.

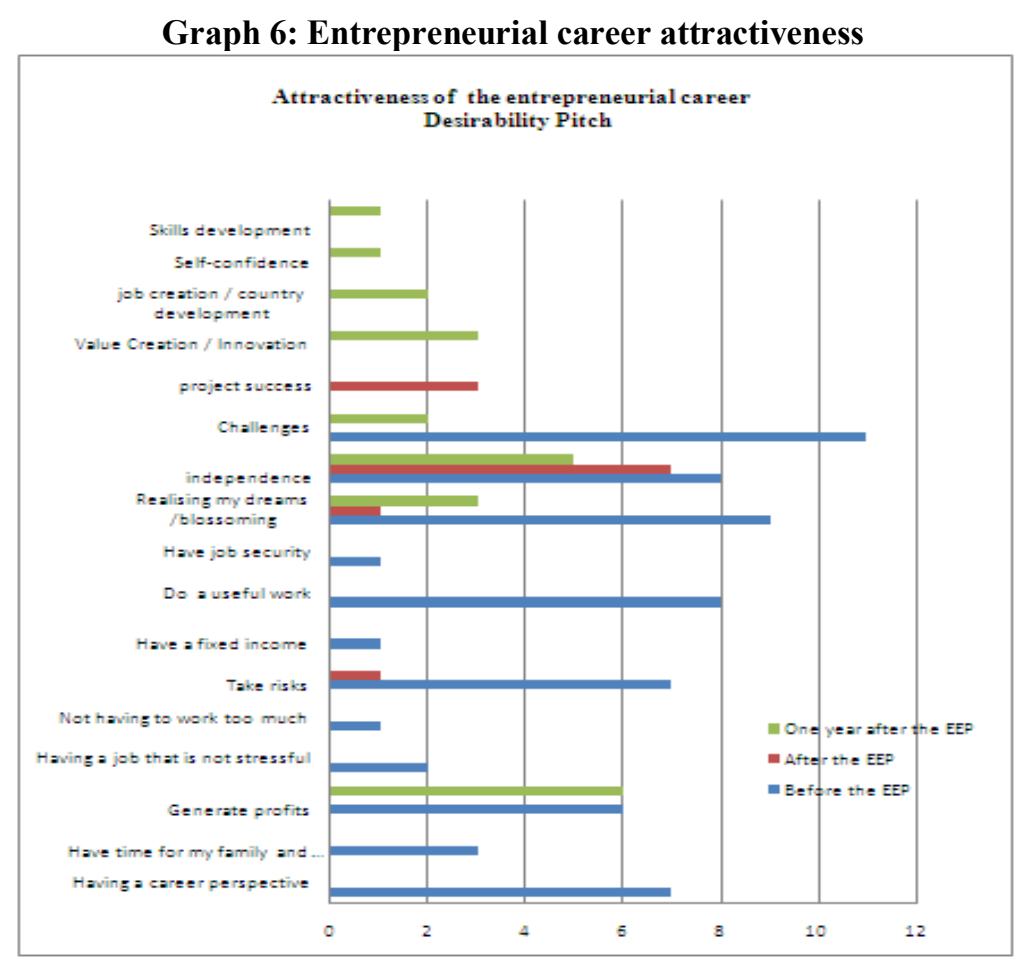


This graph shows the desirability arguments related to career attractiveness raised by the participants through the 3 stages. We note that there are only two elements that are recurrent on the three steps: independence, dreams achievement and personal development. This reflects an important link between these data and the attractiveness of the entrepreneurial career.

Other factors mentioned by several people in step 1, are no more cited in step 2 but are brought up (even if it is to a lesser extent) in step 3, we can cite for example: profits generation and challenges.

Finally, some elements appear only in step 3 such as skills development; self-confidence; job creation; value creation and innovation.

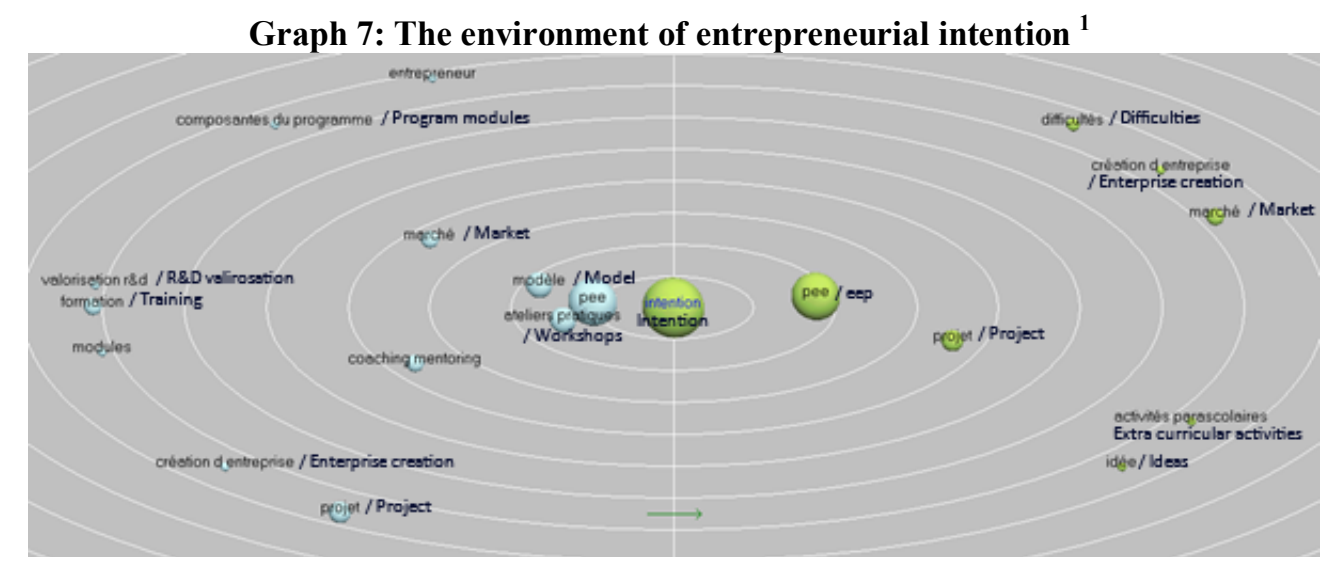

Through the analysis of entrepreneurial intention environment from the subjects verbatim, the aspect that appears first is that entrepreneurial role models can be the antecedent of entrepreneurial intention. Moreover, practical workshops are the first module related to entrepreneurial intention, followed by coaching/mentoring and market conditions.

\section{Concluding remarks}

As a global concluding remark, we can say that for the studied group the overall entrepreneurial intention generally evolved positively. However, some subjects changed their mind once they were aware of the market.

Moreover, we think that a role model is an important issue for both the origin of entrepreneurial intention as well as for its development.

Some additional results raised by the consolidation of the 3 steps can be summarized as follows:

- The desirability of the entrepreneurial career is stable throughout the whole study period.

- Desirability is mainly related to challenges, dreams, self-development, independence and benefits realization.

- Entrepreneurial intention has globally evolved positively just after the EEP but for some evolved negatively after a year.

- The desired timing to start a business is almost stable over the three periods and it is best sought as after 05 years of professional experience.

- Feasibility is

- related primarily to incubation and support mainly just after the EEP. However, it is the funding that is recurrent on the 3 steps.

Entrepreneurial attitude evolves positively after the EEP and one year later.

\section{Entrepreneurship educators}

\section{Introducing A Eep In An Engineering School:}

For us, becoming an entrepreneurship educator requires a fair capacity of adaptation and an important personnel development that would allow educators to become more creative and capable of inspiring entrepreneurial students.

Indeed, the role of educators in the development of the student's "savoir-être" is essential. It is therefore important to get entrepreneurship educators to be aware of the specific issues of this education.

This assumes, however, that these educators are open-minded and accept to question and challenge traditional methods of teaching.

\footnotetext{
${ }^{1}$ See the original graph in French on Annex 1
} 
According to an experiment conducted in France and reported by Dervaux (2011) [23], to make entrepreneurship educators aware of the best business practices, pairs of teachers and entrepreneurs were trained together.

Each one is required to share a day in the other's life, allowing him to discover the concerns and environment of his pair helping create bonds of trust between them.

To this end, the selection of educators for an entrepreneurship education program is, in our opinion, a process to be conducted with a great vigilance. It is very important to ensure that we are building dynamic teams who are willing to share their passion with students.

Finally, it seems necessary to determine the means that will allow us to make the teaching world progress, specially that it seems particularly apart from entrepreneurs identities, professional values and learning practices (Verzat, 2011) [24].

\section{Assessment practices}

Given the diversity of entrepreneurship education programs as well as their contents, objectives, target population etc., their evaluation is still unclear for number of researchers.

However, there are some results that describe the types of assessments that can be used in these programs. They can be summarized as follows (Fayolle, 2011) [25]:

- The evaluation of the programs relevance to the needs and expectations of all parties (i.e. society, organizations and individuals);

- The consistency of the program's components: participants; objectives; content; methods; means ...;

- The programs efficiency: Measuring if the objectives have been met and whether they have been achieved at a lower cost.

Moreover, the evaluation of the impact of these programs is generally done through the assessment of the direct impact such as: the number of new businesses and new jobs created; or the indirect impact: by measuring the evolution of entrepreneurial intention, entrepreneurial spirit....

However, it should also be noted in this regard that it is difficult to measure the acquired skills (general or entrepreneurial) through these programs.

\section{Overcoming resistance in a school of engineering}

We believe that currently in Morocco, in line with many other countries, the government is well aware of the efforts needed in education for the development of entrepreneurship. We will, thus, limit ourselves to the discussion of the resistance met in a school of engineering.

The Moroccan prestigious engineering schools are constituted by an elitist frame reproduced from the French model of engineering schools.

The educational system of these schools is very different from the one of higher education institutions in North America. Given their flexibility, these institutions promote the development of a culture favorable to an entrepreneurial behavior.

Moreover, in Morocco, access to the most prestigious schools of engineers is determined by the classification in a National Competition (CNC) and the passage of engineering students by recognized preparatory classes.

These years of preparation, necessary to integrate engineering schools and followed by a competition that will determine their access to the best schools, are not favorable to the development of entrepreneurial behavior.

In addition, the "engineer" profile has long been considered as a selective and elitist profile. It is therefore, more difficult to convince students to adopt different behaviors of those favored by the system, and to convince schools to develop activities and courses that would encourage the development of these skills.

Furthermore, the resistance lies also within the professors of these schools, who generally don't consider entrepreneurship as a discipline consistent with the engineering training. They think in fact, that the engineer is a profile that rather requires the development of scientific capabilities.

However, through our experience in a Moroccan school of engineering as well as various researches done within partner schools, we can say that there is now a growing awareness on both the students side as well as on the decision-making bodies for the benefits of these skills acquisition by engineering students.

It would therefore be appropriate to facilitate the adoption of a broader vision of entrepreneurship that emphasizes the objectives of this education and the benefits that can be derived from an entrepreneurial pedagogy rather than setting objectives related to value production (Verzat, 2011) [26]. 


\section{How can we encourage the acquisition of entrepreneurial skills in a school of engineering?}

The first principle that we consider of great importance for the development of an entrepreneurial culture within an engineering school is the support and encouragement of extracurricular activities. It seems to us, however, that this element is well developed in our engineering schools in Morocco. teaching.

The second point to develop in these schools would be the integration of active learning techniques in

The third step could be the adoption of a competency-based approach that will go from the definition of needed competencies by an engineer before defining the courses content. This approach would certainly highlight many entrepreneurial skills.

A final element is the development of student's mobility (cultural, professional, geographic ...). In our opinion as well as other researchers (Fayolle, 2011) [27], this would greatly facilitate the development of entrepreneurial behavior.

At last, we believe that these skills acquisition should be done through an entrepreneurship integrated process from which we can cite: training, research, incubation, culture of creativity and innovation, support activities and the development of partnerships with the social and professional environment.

This cannot be achieved without a concrete and constant support of the school's management and through the availability of human and financial resources necessary to the development of such activities.

\section{Conclusion}

Entrepreneurship education is now gaining legitimacy across the Moroccan educational system. Most senior officials are already aware of the issues related to this area especially for young students in schools with high potential for innovation and creativity, namely engineering schools.

We believe that entrepreneurship education can be of a great contribution for engineering students whether they are employees or entrepreneurs. Whether in an administration, a business or a startup; the acquired skills will be useful both in their professional and personal life.

It is therefore, more and more common in our country to find training opportunities, support, funding, mentoring, etc. designed to encourage young project holders to go further in their entrepreneurial adventure.

National or international initiatives do exist and have never been so acclaimed by our youth. However, it remains, in our opinion, necessary to conduct a combination of efforts among the sector's various players in order to reach an overall strategy and most eloquent results.

Moreover, from the evaluation of the pilot project in INPT, the results have showed a good response to the objectives of the EEP by the students and a positive evolution of entrepreneurship intention.

\section{Books:}

\section{References}

[1]. P. F. Drucker, Innovation and Entrepreneurship, Practices and Principles (HarperCollins Publishers, 1985).

Journal Papers:

[2]. C. Verzat, B.Surlemont, Éduquer à l'entrepreneuriat : défis et pratiques d'aujourd'hui, Entreprendre \& Innover, 2011

[3]. A. Fayolle; B. Gailly; N. Lassas-Clerc, "Assessing the impact of entrepreneurship education programs: a new methodology", Journal of European Industrial Training Vol. 30 No. 9, 2006 pp. 701-720

[4]. R.Gibbs, The intentionalist controversy and cognitive science. Philosophical Psychology, 6 , 1993, $175-199$.

[5]. Z. Aouni, Démystification d'une pédagogie émergente : l'approche par les compétences, Entreprendre \& Innover, 2011/3 n ${ }^{\circ} 11-12$, p. $120-126$.

[6]. C. Verzat, B.Surlemont, Éduquer à l'entrepreneuriat : défis et pratiques d'aujourd'hui, Entreprendre \& Innover, 2011

[7]. S. Bureau and J. Fendt, Dériver pour apprendre à entreprendre..., Entreprendre \& Innover, 2011/3 n 11-12, p. 86-94.

[8]. E.S. Mwasalwiba, Entrepreneurship education: a review of its objectives, teaching methods, and impact indicators, Education + Training, Emerald Group Publishing Limited, 2010.

[9]. H. Matlay, Researching entrepreneurship and education. Part 2: What is entrepreneurship and does it matter?, UCE Business School, Birmingham, UK Education + Training. Vol $48 \mathrm{~N}^{\circ} 8 / 9,2006$, pp. 704-718, Ens. E4

[10]. A. Fayolle, Enseignez, enseignez l'entrepreneuriat, il en restera toujours quelque chose !, Entreprendre \& Innover, ${ }^{\circ} 11-12,2011 / 3$, p. 147-158.

[11]. C. Verzat, Expérimenter et coopérer pour apprendre à entreprendre, Un livre de référence pour les équipes pédagogiques des cursus d'entrepreneuriat, Entreprendre \& Innover, n 11-12, 2011/3, p. 113-119.

[12]. I. Ajzen, The theory of planned behavior. Organizational Behavior and Human Design Processes, 1991, 50, $179-211$.

[13]. A. Bandura, The assessment and predictive generality of self-percepts of efficacy, Journal of Behavior Therapy and Experimental Psychiatry, 13, 1982, 195-199.

[14]. A. Shapero, L. Sokol, The Social Dimensions of Entrepreneurship, in C. Kent, D. Sexton, and K. H. Vesper (eds.) The Encyclopedia of Entrepreneurship. Englewood Cliffs, NJ: Prentice -Hall. (1982).p. 72-90.

[15]. A. Fayolle, B. Gailly; N. Lassas-Clerc, Assessing the impact of entrepreneurship education programs: a new methodology, Journal of European Industrial Training Vol. 30 No. 9, 2006, pp. 701-720.

[16]. N.F. Krueger and D.V. Brazeal, Entrepreneurial potential and potential entrepreneurs. Entrepreneurship Theory and practice, 18, 1994, 91-104.

[17]. A. Fayolle, B. Gailly; N. Lassas-Clerc, Assessing the impact of entrepreneurship education programs: a new methodology, Journal of European Industrial Training Vol. 30 No. 9, 2006, pp. 701-720.

[18]. C. Dervaux, « Vis ma vie » et découvre mon entreprise..., Entreprendre \& Innover, 2011/3 n 11-12, 2011, p. 95-102. 
[19]. C. Verzat, Expérimenter et coopérer pour apprendre à entreprendre, Un livre de référence pour les équipes pédagogiques des cursus d'entrepreneuriat, Entreprendre \& Innover, nº 11-12, 2011/3, p. 113-119.

[20]. A. Fayolle, Enseignez, enseignez l'entrepreneuriat, il en restera toujours quelque chose !, Entreprendre \& Innover, $n^{\circ} 11-12,2011 / 3$, p. $147-158$.

[21]. C. Verzat, Expérimenter et coopérer pour apprendre à entreprendre, Un livre de référence pour les équipes pédagogiques des cursus d'entrepreneuriat, Entreprendre \& Innover, n 11-12, 2011/3, p. 113-119.

[22]. A. Fayolle, Enseignez, enseignez l'entrepreneuriat, il en restera toujours quelque chose !, Entreprendre \& Innover, n ${ }^{\circ} 11-12,2011 / 3$, p. $147-158$.

\section{Annex 1: The environment of entrepreneurial intention (original graph in French)}

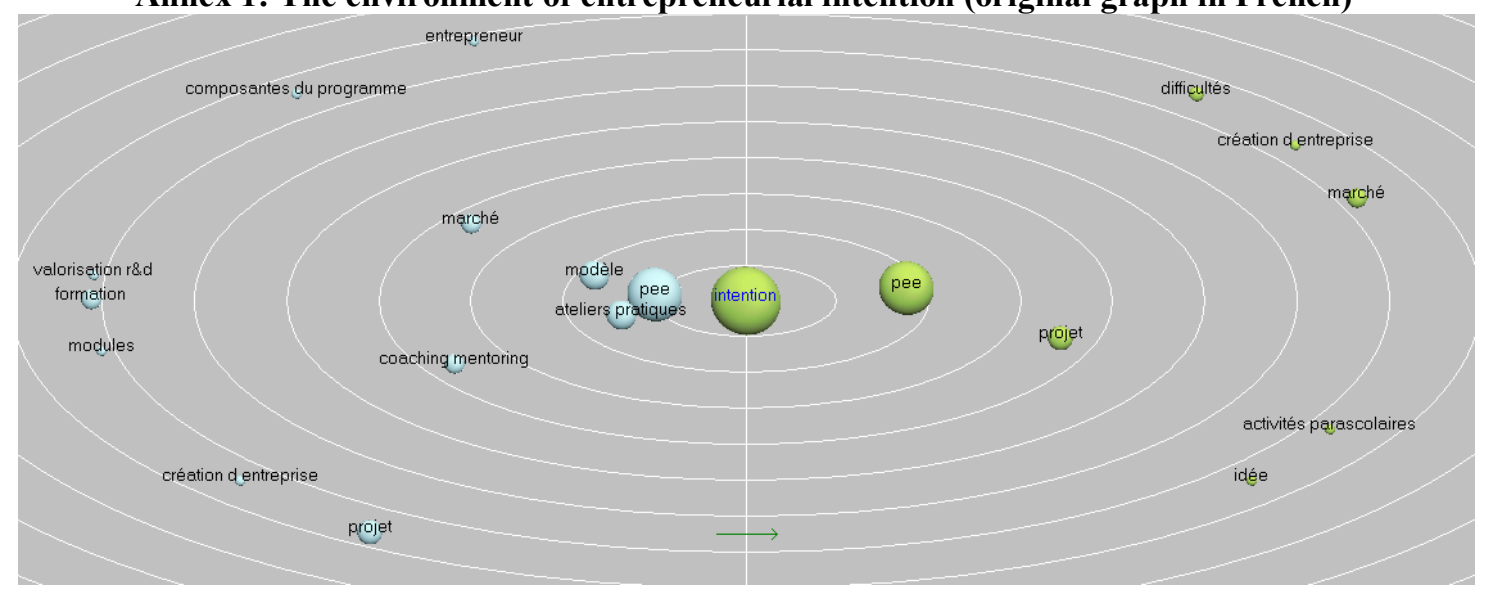

